\title{
Neurosyphilis after treatment of latent syphilis with benzathine penicillin
}

\author{
JøRGEN JøRGENSEN, GYRD TIKJøB, AND KAARE WEISMANN \\ From the Department of Dermatology and Venereology, Bispebjerg Hospital, Copenhagen, Denmark
}

SUMMARY Two patients developed neurosyphilis after treatment of latent syphilis with intramuscular benzathine penicillin. The cases confirm recent investigations that show that neither benzathine penicillin nor procaine penicillin in the standard doses results in treponemicidal concentrations of penicillin in cerebrospinal fluid. Neurosyphilis can be treated effectively by intravenous benzylpenicillin infusions of 18 to $21.6 \mathrm{~g}$ daily for 15 days.

\section{Introduction}

Benzathine penicillin $G$ and procaine penicillin $G$ are the antimicrobial agents most commonly used to treat syphilis. Common regimens for the treatment of early syphilis are intramuscular injections of benzathine penicillin G $1.8 \mathrm{~g}$ weekly for three successive weeks, or procaine penicillin $\mathrm{G} 0.36 \mathrm{~g}$ daily for 10 days. These doses ensure a higher continuous concentration of penicillin in the blood than $0.018 \mathrm{mg} / \mathrm{l}$ for more than 10 days. ${ }^{1}$ If the concentration of penicillin falls below this limit for more than 24 to 36 hours, the treponemes may reproduce. Recent investigations have shown that neither of these regimens, even if administered in double doses or in combination with oral probenecid, results in therapeutic concentrations of penicillin in the cerebrospinal fluid (CSF). ${ }^{2-4}$

Thus treatment failure can be expected to occur in patients with syphilic infection of the central nervous system. Two cases are reported here.

\section{Case reports}

CASE 1

A Turkish bisexual man aged 57 attended the clinic for venereal diseases for a routine examination. Syphilis serology showed a positive Wassermann's reaction, Kahn's reaction, and Meinicke's reaction, and positive results to fluorescent treponemal antibody-absorbed (FTA-ABS) and Treponema pallidum immobilisation (TPI) tests. He had no history of primary or secondary syphilis and presented no clinical signs of active

Address for reprints: Dr K Weismann, Department of Dermatology and Venereology, Bispebjerg Hospital, Bispebjerg Bakke 23, 2400 København NV, Denmark

Accepted for publication 17 September 1985 infection. He was treated with intramuscular benzathine penicillin (Penilente) $1.8 \mathrm{~g}$ a week for three weeks.

Routine syphilis serology tests four weeks after the treatment showed no change in titres of the cardiolipin antibodies. He did not attend for further follow up. Three months later he was referred from another hospital where he had been admitted with fever, generalised weakness, headache, tinnitus, paresis of the facial nerve, and decreased sensation and power of his right fourth and fifth fingers. The symptoms had developed one month after the third injection of benzathine penicillin. Investigation of the CSF showed a positive Wassermann's reaction, a doubtfully positive Meinicke's reaction, and strongly positive results to FTA-ABS and TPI tests. CSF protein concentrations were marginally raised (550 $\mathrm{mg} / \mathrm{l})$ and the white cell count was $9 \times 10^{9} / \mathrm{l}$. Ophthalmological and otological examinations were normal. He was treated in hospital with penicillin $18 \mathrm{~g}$ a day for 15 days administered intravenously. After the treatment there was a rapid improvement of his general health and a slow but definite resolution of the neurological symptoms, which had almost disappeared after about three months. The titre of cardiolipin antibodies shown by the Wasserman reaction had then decreased.

\section{CASE 2}

A homosexual man aged 25 had been treated five years previously with benzathine penicillin for latent syphilis. Within four months after treatment the titre of cardiolipin antibody shown by the Wassermann reaction had decreased to zero. Four years later he was considered to have been reinfected with syphilis. Though the clinical findings were normal, cardiolipin 
antibody tests (Wasserman's, Kahn's and Meinicke's reactions) and the TPI test gave strongly positive results, and latent syphilis was diagnosed. He was treated with benzathine penicillin $1.8 \mathrm{~g}$ a week for three weeks. He failed to attend for follow up.

The patient was seen one year later because of perianal eczema and rectal gonorrhoea. Dark field examination was negative. Wassermann's and Meinicke's reactions and automated reagin tests gave positive results. The gonorrhoea was treated with sulphametizole-trimethoprim $400 / 80 \mathrm{mg}$, five tablets given twice at an eight hour interval.

$\mathrm{He}$ attended the clinic again one month later. His right pupil had been dilated for two weeks and he had influenza like symptoms. Syphilis serology results were unchanged. Investigation of the CSF showed pronounced leucocytosis $\left(47 \times 10^{9} / 1\right)$ and an increased protein concentration of $1.48 \mathrm{~g} / \mathrm{l}$. The Wassermann's reaction in the CSF was positive. There were no neurological symptoms but ophthalmological examination showed a dilated right pupil that reacted slowly to light. He was treated with intravenous benzylpenicillin $18 \mathrm{~g}$ daily for 15 days, and a noticeable improvement of the pupillary defect had occurred after six weeks.

\section{Discussion}

Both patients had received standard treatment with benzathine penicillin. Despite this they developed symptomatic neurosyphilis after one and 12 months respectively. A parallel case was reported by Green $e t$ $a l$, whose patient developed atypical basal meningitis one year after treatment with intramuscular benzathine penicillin $6.48 \mathrm{~g}$ for latent syphilis. ${ }^{5}$ (Paresis of the oculomotor nerve developed and the CSF showed an increased cell count and protein concentration and a positive Venereal Disease Research Laboratory (VDRL) test. Three months after treatment with intravenous benzylpenicillin $18 \mathrm{~g}$ daily for 21 days the paresis had resolved and the CSF was almost normal.

In a recent review of neurosyphilis, Stöckli emphasised that the common treatment regimens with benzathine penicillin and procaine penicillin do not ensure a treponemicidal concentration of penicillin in the CSF. ${ }^{2}$ Frentz et al showed that intramuscular benzathine penicillin at a dose of 1.8 did not produce treponemicidal concentrations in the CSF in 17 of 18 patients. $^{3}$ This confirmed an earlier American investigation in which only one of 13 patients treated with benzathine penicillin $2.7 \mathrm{~g}$ weekly for four weeks showed measurable concentrations of penicillin in the CSF. ${ }^{6}$ Goh et al reported that in five of 11 patients treated with procaine penicillin intramuscularly plus $2 \mathrm{~g}$ probenicid by mouth, the CSF concentration of penicillin did not reach the limit of $0.018 \mathrm{mg} / \mathrm{l}$ as measured two to three hours after the injections, which were given for two to three weeks. ${ }^{4}$ In three of the patients no penicillin could be detected in the CSF. A separate group of 10 patients was treated with procaine penicillin $0.36 \mathrm{~g}$ daily for 10 days without probenicid. In no case did the concentration of penicillin in the CSF exceed $0.018 \mathrm{mg} / \mathrm{l}$. In all 21 patients the serum penicillin concentration was far above the treponemicidal level. Ducas and Robson found that treatment with benzathine penicillin $1.8 \mathrm{~g}$ and $3.6 \mathrm{~g}$ intramuscularly combined with probenicid $2 \mathrm{~g}$ orally, as in the case of procaine penicillin, did not result in sufficient concentrations of penicillin in the CSF. ${ }^{8}$ By administering water soluble benzylpenicillin 18 to $21.6 \mathrm{~g}$ a day intravenously a safe treponemicidal CSF penicillin concentration can be ensured. ${ }^{29}$

Isolation of $T$ pallidum from the CSF has been reported in a patient suffering from neurosyphilis who had been treated with intramuscular benzathine penicillin $0.9 \mathrm{~g}$ three times a week for three weeks. ${ }^{10}$ Two treatment failures have been found in 26 patients treated for neurosyphilis with benzathine penicillin. ${ }^{11}$ Hooshmand et al reported that after treatment with intramuscular procaine penicillin 18 to $21.6 \mathrm{~g}(1.8 \mathrm{~g}$ every two days) for three weeks, five of 89 patients showed clinical progession of neurosyphilis, while the CSF cell count and protein concentrations remained normal. ${ }^{12}$ Ten patients with tabes dorsalis or meningovascular syphilis still showed active neurosyphilis and CSF leucocytosis after treatment with $8 \cdot 1$ g penicillin. ${ }^{12}$

The reported cases of treatment failure emphasise the importance of investigating the CSF of all patients with latent syphilis of unknown duration or of more than one year's duration. Furthermore, a spinal puncture is warranted in patients who fail to show a pronounced decrease in the serum cardiolipin antibody titres after receiving standard penicillin treatment for syphilis.

\section{References}

1 Anonymous Treponemal infections. WHO Tech Rep Ser 1982;674:35-9.

2 Stöckli HR. Neurosyphilis heute. Dermatologica 1982;165:23248.

3 Frentz G, Nielsen PB, Espersen F, Czartoryski A, Aastrup H. Penicillin concentrations in blood and spinal fluid after a single intramuscular injection of penicillin $\mathrm{G}$ benzathine. Eur $J$ Clin Microbiol 1984;3:147-9.

4 Goh BT, Smith GW, Samarasinghe L, Singh V, Lim KS. Penicillin concentrations in cerebrospinal fluid and serum after inramuscular injection of aqeous procaine penicillin $0.6 \mathrm{MU}$ with and without probenecid. British Journal of Venereal Diseases 1984;60:371-3.

5 Green BM, Miller N, Bynum T. Failure of penicillin G benzathine in the treatment of neurosyphilis. Arch Intern Med 1980;140:1117-8.

6 Yoder FW. Penicillin treatment of neurosyphilis. JAMA 1975;232:270-1. 
7 Dunlop EM, Al-Egaily SS, Houang ET. Penicillin levels in blood and CSF achieved by treatment of syphilis. JAMA 1979;241:2538-40.

8 Ducas J, Robson HG. Cerebrospinal fluid penicillin levels during therapy for latent syphilis. JAMA 1981;246:2583-4.

9 Löwhagen G-B, Brorson J-E, Kaijser B. Penicillin concentrations in cerebrospinal fluid and serum after intramuscular, intravenous and oral administration to syphilitic patients. Acta Derm Venereol (Stockh) 1983;63:53-7.
10 Tramont EC. Persistence of Treponema pallidum following penicillin $G$ therapy. JAMA 1976;236:2206-7.

11 Short DH, Knox JM, Glicksman J. Neurosyphilis, the search for adequate treatment. Arch Dermatol 1966;93:87-91.

12 Hooshmand H, Escobar MR, Kopf SW. Neurosyphilis. A study of 241 patients. JAMA 1972;219:726-9. 